\title{
Isolation of Amniotic Fluid Mesenchymal Stem Cells Obtained from Cesarean Sections
}

\author{
Bobby Indra Utama ${ }^{1,2 *}$, Afriwardi Afriwardi ${ }^{3}$, Budi Iman Santoso ${ }^{4}$, Hirowati Ali ${ }^{5}$ \\ ${ }^{1}$ Doctoral Students of Biomedical Science, Faculty of Medicine, Andalas University, Padang, West Sumatera, Indonesia; \\ ${ }^{2}$ Department of Obstetrics and Gynecology, Faculty of Medicine, General Hospital of Dr. M. Djamil, Padang, West Sumatera, \\ Indonesia; ${ }^{3}$ Department of Physiology, Faculty of Medicine of Andalas University, Padang, West Sumatera, Indonesia; \\ ${ }^{4}$ Department of Obstetrics and Gynecology, Faculty of Medicine, University of Indonesia, Jakarta, Indonesia; ${ }^{5}$ Department of \\ Biochemistry, Faculty of Medicine, Andalas University, Padang, West Sumatera, Indonesia
}

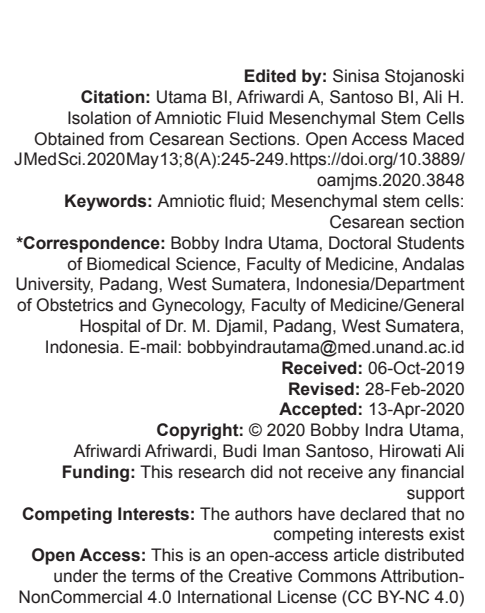

\section{Abstract}

BACKGROUND: The term amniotic fluid (AF) can be an ideal alternative as a source of mesenchymal stem cells (MSCs), originating from the neonate. Preclinical studies of the second- and third-trimester amnion fluid cells confirmed the number of potential donors from this wasted material.

AIM: This study aims to look at the forming time of stem cells derived from AF-MSCs.

MATERIALS AND METHODS: AF samples from healthy human donors were collected during full-term C-sections and kept at $4^{\circ} \mathrm{C}$ until processed. The number of colony-forming unit-fibroblast was assessed microscopically by calculating spindle-shaped colonies that clearly resembled of fibroblasts and did not include colonies with rounded epithelioid morphology. The immunophenotyping of their independent AF preparations was done using the human MSC phenotyping kit which was done according to the manufacturer's instruction by flow cytometry.

RESULTS: The result showed that it succeeded in getting 8 million cells which will be used for research on pelvic organ prolapse therapy using AF-MSCs. The stem cell isolation totally takes 6 weeks. We got 2 million stem cells in one flask.

CONCLUSION: This study concludes that the time needed for differentiation of AF-MSCs is 6 weeks and AF-MSCs express mesenchymal markers such as CD90, CD73 (SH3, SH), and CD105 (SH2) and these cells also express HLA antigens - ABC, CD 34, and CD 45 which are hematopoietic markers and endothelial CD31 markers.

\section{Introduction}

Amniotic fluid $(A F)$ is a liquid that fills the amniotic cavity which has defense and nutritional functions in fetal development. The volume and composition of AF can be changed according to the age of the pregnancy. At the beginning of fetal development, AF is produced by the maternal plasma. In 8 weeks of gestation, the kidneys begin to produce fluids that significantly add AF. Recent findings on stem cell sources show that AF contains novel stem cells (AFS = AF stem cell), characterized by c-kit expression (stem cell factor receptor), illustrating that AFS can be used in regenerative medicine [1].

There is a heterogeneous population of the three developmental plates in AF. In this tissue, cells are found from the inner layer of the amniotic membrane (AM) or from developing fetal cells. Cells in AF are grouped based on morphology, growth, and biochemical characteristics. Epithelioid cells ( $E$ type) are cuboid to columnar cells that originate from the skin and urine of the fetus, AF cells (AF type) from fetal membranes (AF type), and fibroblastic ( $F$ type) cells originating from connective tissue fibrous. Immunophenotypes showing AF stem cells are dominated by mesenchymal stem cells (MSCs) known as AF-derived MSCs (AF-MSCs) [2].

MSCs are multipotent and self-renewal cells. In the study of Asl et al., comparison between mesenchymal cells originating from human amnion and mesenchymal cells originating from adipose cells. In this study, a higher proliferative power was obtained in mesenchymal cells originating from human amnion compared to those derived from human adipose cells. In the study of Gaafar et al., a comparison is made between MSC on amnion, endometrium, and ovary. All three have almost the same molecular structure, but MSC derived from AF has a lower immune response and higher transplant success in xenogenetic hosts [3], [4].

Human term AF can be an ideal alternative as a source of MScs, originating from the neonate. Preclinical studies of the second- and third-trimester amnion fluid cells confirmed the number of potential donors from this wasted material. Human AF stem cells 
(hAFSCs) can be obtained noninvasively. hAFSCs have proliferative rates, induce immunological tolerance, describe embryonic stem cell (ESC) properties, and can differentiate into three developmental plates and several cell lineages, such as adipocytes, osteoblasts, chondrocytes, kidney cells, hepatocytes, and cardiomyocytes. This characteristic suggests that hAFSC can be an ideal source of application for stem cell therapy [5], [6].

AF has an essential function in fetal development, nutrition, and defense. The volume and composition of AF already changed according to the age of the pregnancy. AF is also used for screening of genetic disorders, embryos, infections, and congenital disorders. Besides that, AF has some variety of stem cells from developing fetuses which can be a source of stem cell development [1], [7].

AF is a promising source of stem cells. AF is found in many types of stem cells, from primordial cells that are pluripotent to specific organ progenitor cells and adult cells. In addition, hematopoietic progenitor cells and genetic markers of specific tissues such as the brain, heart, and pancreas were also found. Recently, AF has become a source of MSCs for therapeutic therapy with minimal risk of tumor formation [1], [8].

Tsai et al. (2004) in their study succeeded in isolating AF-MSC in the second trimester of pregnancy. Isolation was obtained without disturbing the karyotype process of the fetus using the novel two-stage culture protocol method. Cells obtained from this process can develop into several cell types in vitro [9].

\section{Materials and Methods}

This is an experimental research with post-testonlly control group design. The sample used in this study amounted to three patients. The study was conducted in the biomedical laboratory and the laboratory of Institute of Medical Education and Research in Indonesia, Faculty of Medicine, University of Indonesia.

\section{Inclusion and exclusion criteria}

A term gestational age (37-41 weeks), the patient does not have other comorbid diseases, AF is normal, in healthy AF, cells develop well until passage 3 and there is no contamination during the culture process and exclusion criteria are failed to breed cells.

\section{Preparation of AF-MSCs}

There AF samples from healthy human donors were collected during full-term $\mathrm{C}$-sections and kept at $4^{\circ} \mathrm{C}$ until processed. In general, the time between collection and processing was kept as short as possible to minimize cell death. First, AF was washed with phosphate-buffered saline (PBS) and centrifuged at $300 \times \mathrm{g}$ for $5 \mathrm{~min}$. The supernatant was discarded, and the pellet washed again with PBS. Thereafter, the cell solution was incubated at $4^{\circ} \mathrm{C}$ for $20 \mathrm{~min}$ and centrifuged again. This procedure was repeated until the pellet had a clear color. Afterward, the cells were cultured in Chang C Medium containing $88 \%$ a-mem with $10 \%$ fetal bovine serum, 1\% Glutamax, 1\% penicillin/streptomycin, 10\% Chang B Basal Medium, and 2\% Chang C supplement at $37^{\circ} \mathrm{C}$ and $5 \% \mathrm{CO}_{2}[10]$.

\section{Colony-forming unit-fibroblast (CFU-F) assays}

After 11-14 days of cell culture, the number of CFU-F was assessed microscopically by calculating spindle-shaped colonies that clearly resembled fibroblasts and did not include colonies with rounded epithelioid morphology. Colonies containing $\geq 40$ cells were counted [5]. The AF culture was carried out in the biomedical laboratory of Andalas University.

\section{Flow cytometric analysis of AF-MSCs}

The immunophenotyping of their independent AF preparations was done using the human MSC (hMSC) phenotyping kit which was done according to the manufacturer's instruction. After harvesting, $2 \times 10^{5}$ AF-MSCs were transferred into two test tubes. A $2 \mathrm{ml}$ PBS was added to each tube and centrifuged at $300 \times \mathrm{g}$ for $5 \mathrm{~min}$. The supernatant was discarded and the pellet resuspended in $100 \mathrm{ul}$ PBS within the tubes. In one of the tubes, $0.5 \mathrm{ul}$ of the MSC phenotyping cocktail and the other tube $0.5 \mathrm{ul}$ of isotype control cocktail were added and vortexed. The MSC phenotyping cocktail contained fluorochrome-conjugated monoclonal antibodies CD73-APC, CD90-FITC, and CD105-PE. The isotype phenotyping cocktail contained fluorochromeconjugated antibodies that should not, especially, detect human antibodies and was, therefore, used as a negative control. The tubes were incubated at $4^{\circ} \mathrm{C}$ for 10 min in the dark until flow cytometric analysis through BD FACSCanto was done [10].

\section{Statistics}

Data are presented in descriptive form and presented as a percentage.

\section{Research ethics}

This research has received ethical considerations and approval from the Research Ethics Committee Team of the Medical Faculty of Andalas University with registration number 015/KEP/FK/2019. 


\section{Results}

\section{Morphology from AF-MSCs}

From this study, we succeeded in getting 8 million cells which will be used for research on pelvic organ prolapse therapy using AF-MSCs. The stem cell isolation totally takes 6 weeks. We got 2 million stem cell cells in one flask.

Figure 1 shows that cell of AF-MSC resembles fibroblast cells. Haasters et al., (2009), hMSCs are a

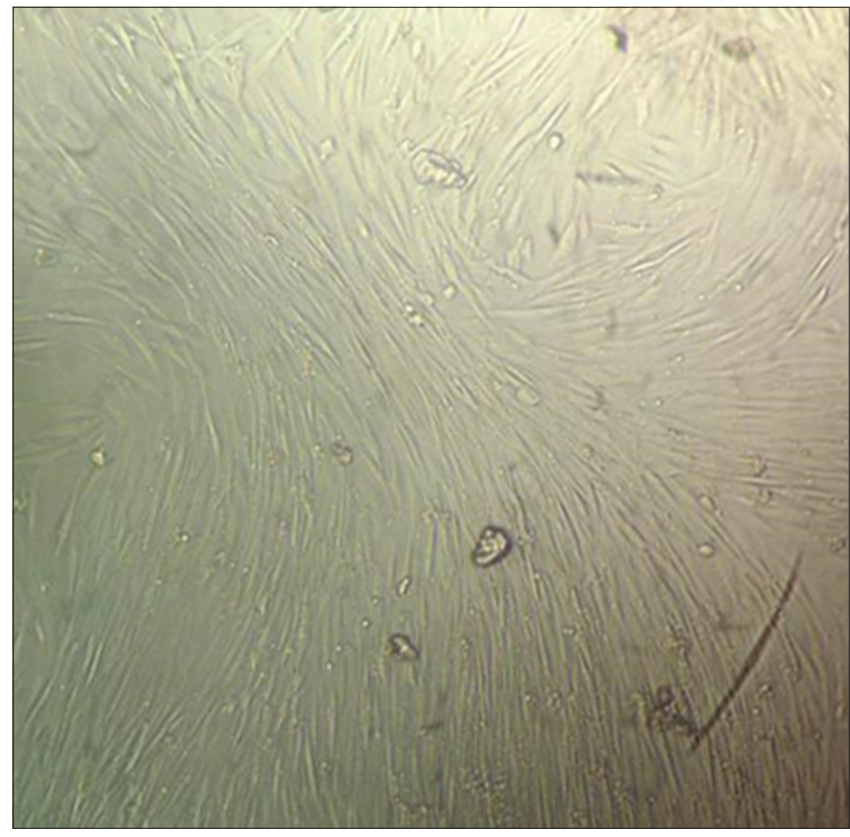

Figure 1: Morphology of amniotic fluid-mesenchymal stem cells

heterogeneous cell population, which are reflected in varying morphological and biological properties. Three subpopulations with intrinsic characteristics can be distinguished as follows: Small rapidly self-renewing cells, spindle-shaped cells, and large, flattened cells [11].

\section{Flow cytometry analysis of AF-MSCs}

Figure 2 shows that marker $C D$ used in this research for AF-MSCs as follows: CD90, CD73, and CD105.

\section{Discussion}

$\mathrm{AF}$ has an essential function in fetal development, nutrition, and defense. The volume and composition of AF already changed according to the age of the pregnancy. AF is also used for screening of genetic disorders, embryos, infections, and congenital

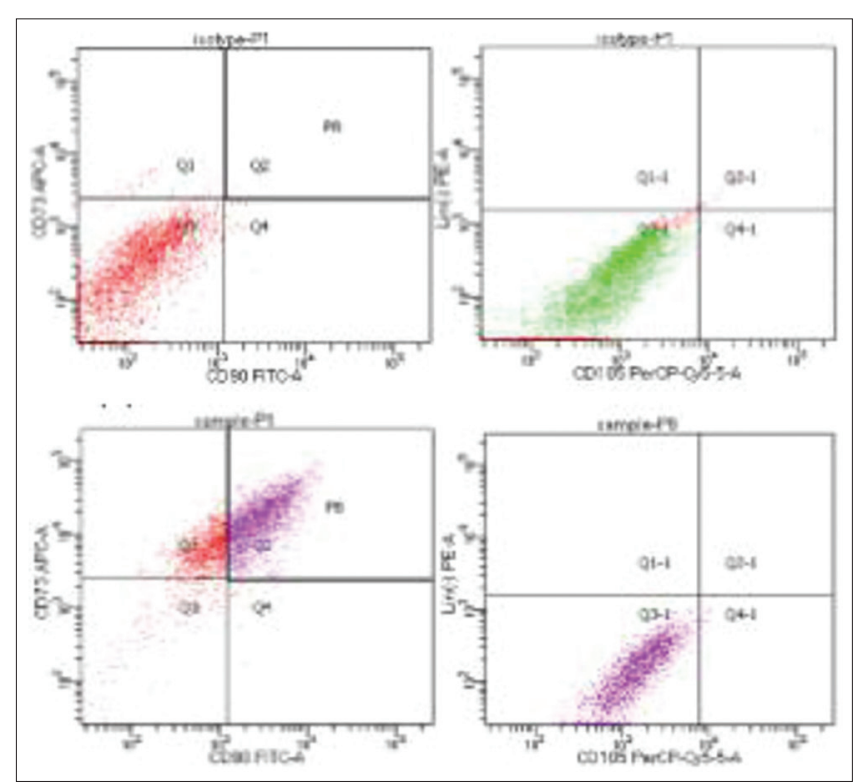

Figure 2: Flow cytometry amniotic fluid-mesenchymal stem cells

disorders. Besides that, AF has some variety of stem cells from developing fetuses which can be a source of stem cell development. Recent findings on stem cell sources show that $A F$ contains novel stem cells (AFS = AF stem cell), characterized by c-kit expression (stem cell factor receptor), illustrating that AFS can be used in regenerative medicine. AF is generally obtained from diagnostic actions of amniocentesis and therapeutic amnioreduction. Although the chemical and cellular composition varies from each gestational age, MSC can be isolated at any time during pregnancy. There are several isolation techniques of AF-MSCs that are commonly used, namely, multiple wells and coverslips. From this study, we succeeded in getting 8 million cells which will be used for research on pelvic organ prolapse therapy using AF-MSCs. The stem cell isolation totally takes 6 weeks. We got 2 million stem cell cells in one flask.

The MSCs, which are derived from the mesoderm, are considered as a readily available source for tissue engineering. They have multipotent differentiation capacity and can be differentiated into various cell types. Many studies have demonstrated that the MSCs identified from the AM (AM-MSCs) and AF (AF-MSCs) are shown advantages for many reasons, including the possibility of non-invasive isolation, multipotency, self-renewal, low immunogenicity, antiinflammatory, and non-tumorigenicity properties, and minimal ethical problem. The AF-MSCs and AM-MSCs may be appropriate sources of MSCs for regenerative medicine, as an alternative to ESCs. Recently, regenerative treatments such as tissue engineering and cell transplantation have shown potential in clinical applications for degenerative diseases [12].

Human AF cells are immune privileged with low immunogenicity and anti-inflammatory properties. They are able to self-renew, are highly proliferative, and have a broad differentiation potential, making them amenable 
for cell-based therapies. AF is routinely obtained through amniocentesis and contains heterogeneous populations of fetal-derived progenitor cells including MSCs. These AF-MSCs showed typical MSC characteristics such as morphology, in vitro differentiation potential, surface marker expression, and secreted factors [10].

Amniotic stem cells (ASCs) can be extracted from the amniotic sac through the amniocentesis process, where this process can be carried out without injuring the developing fetus. This is very important to emphasize because of the negative stigma toward embryonically derived stem cells. Another study showed isolation of $\mathrm{AF}$ through cesarean section labor using a catheter [5], [13].

AF and ASC have many advantages related to medical use. First, fluid and amniotic cells have immunological features which mean that they do not cause a reaction even among donors and recipients who are totally unrelated. Second, the AF contains more stem cells than the adult bone marrow. ASC is like a hybrid between ESCs and adult stem cells in terms of plasticity and differentiation ability. Third, the AF contains hyaluronic acid, which helps lubrication and can be used in the treatment of joints. Fourth, the AF contains a complete complement of growth factors that stimulate stem cells to differentiate into many cell types. Then, AF is naturally antimicrobial and can prevent and eliminate potential infectious agents [13].

In the comparison of AFMSCs with BMSC according to the same growth time (day 15), amniotic cells showed more cells than stem cells originating from the ACS bone marrow. It normally larger and more numerous than stem cells originating from the bone marrow, indicates AFMSCs grow and differentiates faster. This is needed for treatment because it shortens the patient's healing time and can also reduce the amount of treatment needed [13]. AF is generally obtained from diagnostic actions of amniocentesis and therapeutic amnion reduction. Although the chemical and cellular composition varies from each gestational age, MSC can be isolated at any time during pregnancy. There are several isolation techniques of AF-MSCs that are commonly used, namely, multiple wells and coverslips [14].

In the coverslips method, mechanical separation is obtained by placing a pellet on the cover glass of the object distributed on a $10 \mathrm{~cm}$ collagencoated plate with a cell density of 2-3 million cells in $150 \mathrm{~cm}^{2}$. After $48 \mathrm{~h}$, the cover glass of the object was observed and selected cells containing mesenchymal cells were placed on a $30 \mathrm{~cm}^{2}$ culture plate (containing the 20 mesenchymal medium). The medium is replaced every day following the steps of the multiple wells method [14].

MSC develops according to the growing medium. In analyzing surface antigens with flow cytometry, polymerase chain reaction, and staining of immunocytochemistry, AF-MSCs were expressed the same mesenchymal markers from other sources. In several studies, AF-MSCs express mesenchymal markers such as CD90, CD73 (SH3, SH), CD105 (SH2), CD29, CD166, CD49e, CD58, and CD44 (MHC Class I). These cells also express HLA-ABC antigens, CD 34, and CD 45 which are hematopoietic markers and endothelial CD31 markers. There is no expression of CD10, CD11b, CD14, CD34, CD117, EMA, and HLA-DR, DP, and DQ antigens. Most of AF-MSCs have pluripotent properties which are characterized by the discovery of octamer-binding protein 3/4 (Oct-3/4), transcription factors Nanog (Nanog), and stagespecific embryonic antigen 4 (SSEA-4) on RT-PCR examination [2], [9], [15].

Along with the development of stem cell research, the standard criteria for MSC are needed. The international study for cellular therapy recommends the minimum criteria for determining of MSC. These criteria include derived from the fetus, $\leq 1 \%$ maternal contamination, MSC has plastic adherence properties, can develop to form CFU-F, having specific antigen expression. The population of MSC can express CD105 (Endoglin), CD73, and CD 90 (Thy-1) of $\geq 95 \%$ as measured by cytometry flow. There was a lack of CD45, CD34, CD14 or CD11b, CD79a or CD19, and HLA Class II expressions ( $\leq 2 \%$ positive) and MSC must be multipotent differentiated into osteoblasts, adipocytes, and chondroblasts under in vitro standard conditions [16], [17].

\section{Conclusion}

The time needed for differentiation of AF-MSCs is 6 weeks and AF-MSCs express mesenchymal markers such as CD90, CD73 (SH3, SH), and CD105 (SH2) and these cells also express HLA antigens $A B C, C D 34$, and $C D 45$ which are hematopoietic markers and endothelial CD31 markers.

\section{References}

1. DeSacco SD, DeFilippo RE, Perin L. Amniotic fluid as a source of pluripotent and multipotent stem cells for organ regeneration. Curr Opin Organ Transplant. 2011;16(1):101-5. https://doi. org/10.1097/mot.0b013e3283424f6e

PMid:21157345

2. Roubelakis MG, Trohatou O, Anagnou NP. Amniotic fluid and amniotic membrane stem cells: Marker discovery. Stem Cells Int. 2012;2012:1-9. https://doi.org/10.1155/2012/107836

3. Asl KD, Shafei H, Rad JS, Nozad HO. Comparison of characteristics of human amniotic membrane and human adipose tissue derived mesenchymal stem cells. World J Plast 
Surg. 2016;6(1):33-9.

PMid:28289611

4. Gaafar TM, Hawary RE, Osman A, Attia W, Hamza H, Brockmeier K. Comparative characteristics of amniotic membrane, endometrium and ovarian derived mesenchymal stem cells: A role for amniotic membrane in stem cell therapy. Middle East Fertil Soc J. 2014;19(3):156-70 https://doi org/10.1016/j.mefs.2014.01.002

5. Moraghebi R, Kirkeby A, Chaves P, Rönn RE, Sitnicka E, Parmar M, et al. Term amniotic fluid: An unexploited reserve of mesenchymal stromal cells for reprogramming and potential cell therapy applications. Stem Cell Res Ther. 2017;8(190):112. https://doi.org/10.1186/s13287-017-0582-6

6. Kim BS, Chun SY, Lee JK, Lim HJ, Bae JS, Chung HY, et al. Human amniotic fluid stem cell injection therapy for urethral sphincter regeneration in animal model. BMC Med. 2012;10:94. https://doi.org/10.1186/1741-7015-10-94

PMid:22906045

7. Decoppi P, Bartsch G Jr., Siddiqui MM, Xu T, Santos CC, Perin $L$, et al. Isolation of amniotic stem cell lines with potential for therapy. Nat Biotechnol. 2007;25(1):100-6.

PMid:17206138

8. Savickiene J, Treigyte G, Baronaite S, Valiuliene G, Kaupinis A, Valius $M$. et al. Human amniotic fluid mesenchymal stem cells from second-and third-trimester amniocentesis: Differentiation potential, molecular signature, and proteome analysis. Stem Cells Int. 2015;2015:319238. https://doi.org/10.1155/2015/319238 PMid:26351462

9. Tsai MS, Lee JL, Chang YJ, Hwang SM. Isolation of human multipotent mesenchymal stem cells from second-trimester amniotic fluid using a novel two-stage culture protocol. Hum Reprod. 2004;19(6):1450-6. https://doi.org/10.1093/humrep/ deh279

PMid:15105397

10. Spitzhorn LS, Raman MS, Schwindt L, Ho HT, Wruck W, Bohndorf $\mathrm{M}$, et al. Isolation and molecular characterization of amniotic fluid-derived mesenchymal stem cells obtained from caesarean sections. Stem Cells Int. 2017;2017:5932706. https://doi.org/10.1155/2017/5932706

PMid:29225627

11. Haasters F, Prall WC, Anz D, Bourquin C, Pautke C, Endres $\mathrm{S}$, et al. Morphological and immunocytochemical characteristics indicate the yield of early progenitors and represent a quality control for human mesenchymal stem cell culturing. J Anat. 2009;214(5):759-67. https://doi. org/10.1111/j.1469-7580.2009.01065.x

PMid: 19438770

12. Kim EY, Lee KB, Kim MK. The potential of mesenchymal stem cells derived from amniotic membrane and amniotic fluid for neuronal regenerative therapy. BMB Rep. 2014;47(3):135-40. https://doi.org/10.5483/bmbrep.2014.47.3.289

PMid:24499672

13. Larson A, Gallichio VS. Amniotic derived stem cells: Role and function in regenerative medicine. J Cell Sci Ther. 2017;8(3):1-10

14. Steigman SA, Fauza DO. Isolation of mesenchymal stem cells for amniotic fluid and placenta. Curr Protocol Stem Cell Biol. 2007;1:E2. https://doi.org/10.1002/9780470151808.sc01e02s1 PMid: 18785167

15. Chamberlain G, Fox J, Ashton B, Middleton J. Concise review: Mesenchymal stem cells: Their phenotype, differentiation capacity, immunological features, and potential for homing. Stem Cells. 2007;25(11):2739-49. https://doi.org/10.1634/ stemcells.2007-0197 PMid: 17656645

16. Lim R. Concise review: Fetal membranes in regenerative medicine: New tricks from an old dog? Stem Cells Transl Med. 2017;6(9):1767-76. https://doi.org/10.1002/sctm.16-0447 PMid:28834402

17. Dominici M, Blanc KL, Mueller I, Slaper-Cortenbach I, Marini F, Krause $\mathrm{D}$, et al. Position paper: Minimal criteria for defining multipotent mesenchymal stromal cells. The international society for cellular therapy position statement. Cytotherapy. 2006;8(4):315-7. https://doi.org/10.1080/14653240600855905 PMid:16923606 